\title{
The Prevalence, Incidence, Indications and Outcomes of Peripartum Hysterectomy in Kazakhstan: Data from Unified Nationwide Electronic Healthcare System 2014-2018
}

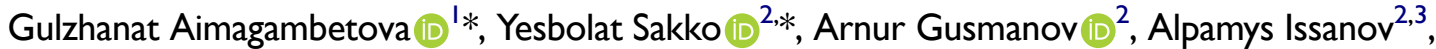 \\ Talshyn Ukybassova ${ }^{4}$, Gauri Bapayeva ${ }^{4}$, Aizada Marat ${ }^{5}$, Aiymzhan Nurpeissova ${ }^{6}$, Abduzhappar Gaipov $\mathbb{D}^{2}$ \\ 'Department of Biomedical Sciences, School of Medicine, Nazarbayev University, Nur-Sultan, Kazakhstan; ${ }^{2}$ Department of Medicine, School of \\ Medicine, Nazarbayev University, Nur-Sultan, Kazakhstan; ${ }^{3}$ School of Population and Public Health, University of British Columbia, Vancouver, Canada; \\ ${ }^{4}$ Clinical Academic Department of Women's Health, National Research Center of Mother and Child Health, University Medical Center, Nur-Sultan, \\ Kazakhstan; ${ }^{5}$ Department of Obstetrics and Gynecology \#I, NJSC “Astana Medical University”, Nur-Sultan, Kazakhstan; ${ }^{6}$ Department of Medical \\ Information Analysis of Outpatient and Polyclinic Care, The Republican Center of Electronic Healthcare, The Ministry of Healthcare of the Republic of \\ Kazakhstan, Nur-Sultan, Kazakhstan
}

*These authors contributed equally to this work

Correspondence: Gulzhanat Aimagambetova, Department of Biomedical Sciences, School of Medicine, Nazarbayev University, Kerey and Zhanibek Khan’s Street 5/I, Nur-Sultan, 0I0000, Kazakhstan, Tel +7 7 I72 694645, Email gulzhanat.aimagambetova@nu.edu.kz

Purpose: Peripartum hysterectomy is a surgical procedure performed as a life-saving surgery to manage severe postpartum hemorrhage. The prevalence of peripartum hysterectomy in high-resource settings is relatively low. However, maternal mortality due to postpartum hemorrhage and after peripartum hysterectomy remains high in developing countries. To date, there is a lack of information about the rates of peripartum hysterectomy and its common indications in Kazakhstan. Objectives were to study the prevalence, indications, and outcomes of peripartum hysterectomy using nationwide large-scale health-care data from the national registry.

Patients and Methods: We performed a descriptive, population-based study among women who underwent a peripartum hysterectomy in any health-care setting of the Republic of Kazakhstan during the period of 2014-2018. Data were collected from the Unified Nationwide Electronic Health System (UNEHS).

Results: Data included 3838 medical records of women who had a peripartum hysterectomy performed due to specific indications for the period of 5 years (2014-2018). The median age of the participants was 33 years old, with $60.7 \%$ of women aged between 18 and 34 years. The leading indications for peripartum hysterectomy were intrapartum hemorrhage (IPH) and postpartum hemorrhage (PPH) reported in $60 \%$ of the cases analyzed. The second most common indication was placental pathology - placental abruption and placenta previa in $9.6 \%$ and $7.9 \%$ of cases, respectively. In 1633 cases $(42.4 \%)$, total abdominal hysterectomy was performed, while subtotal hysterectomy was done in 2195 cases (57.0\%). Based on these data, the estimated prevalence of peripartum hysterectomies was calculated: overall weighted mean prevalence 1.93 per 1000 deliveries.

Conclusion: IPH and PPH are the commonest indications for peripartum hysterectomy followed by placental pathology. Appropriate maternal care during labor and delivery should be reinforced to decrease the incidence of peripartum hysterectomy in Kazakhstan.

Keywords: postpartum hemorrhage, maternal mortality, peripartum hysterectomy, epidemiology, Kazakhstan

\section{Introduction}

Hysterectomy is a surgical procedure in which the uterus (whole or parts) is removed. ${ }^{1-3}$ Hysterectomy is one of the most frequently performed major gynecological surgery in women worldwide. ${ }^{1-5}$ It is estimated that $33 \%$ of women in the United States have had a hysterectomy by the age of 60 . However, similar data are not available from Central Asian countries. 
In obstetric practice, hysterectomy is indicated to manage life-threatening obstetric hemorrhage and uterine sepsis. ${ }^{6,7}$ This approach to treat postpartum bleeding was invented and first performed successfully by Porro in $1871 .^{7}$ Nowadays, emergency peripartum hysterectomy is performed as a life-saving operation only in cases of severe peripartum bleeding related to vaginal delivery or/and cesarean section. ${ }^{7,8}$ Peripartum hysterectomy is defined by the World Health Organization (WHO) as a maternal near-miss criterion, and it is used for the analysis of obstetric outcomes. ${ }^{6,9,10}$

In the systematic review by van den Akker and coauthors (2016), the worldwide prevalence of peripartum hysterectomy was reported 0.9 per 1000 deliveries. $^{7}$ However, the rates may be different between countries. Prevalence of hysterectomy in low- and middle-income settings is much higher than in high-income settings: 10.1 per 1000 deliveries in India ${ }^{7,11}$ compared with 0.2 per 1000 deliveries in Northern European countries. ${ }^{7,12}$

There is a wide range of conditions that may lead to specific obstetric complications, requiring hysterectomy for its management. Postpartum hemorrhage (PPH) is one of the most common indications for hysterectomy in obstetric practice and a leading cause of maternal mortality and severe morbidity. ${ }^{13}$ With the development of medicine and pharmacology, availability of uterotonic medications, blood transfusion, and other invasive hemostatic interventions (O'Leary stitch, B-Lynch sutures, and uterine artery embolization) rates of hysterectomy in obstetric practice may decrease. ${ }^{7,14}$ On the other hand, increasing rates of cesarean delivery lead to a higher incidence of abnormal placental development (placenta accreta, increta, percreta) and subsequent hysterectomy. ${ }^{7,15}$ In the cases of severe hemorrhage, obstetricians are always facing a dilemma, whether to perform a hysterectomy as a life-saving surgery or delay trying to apply other methods. ${ }^{7}$ It is well known that delay in peripartum hysterectomy leads to severe morbidity or maternal death.

Maternal mortality due to PPH and after peripartum hysterectomy varies among countries in the world, with higher rates in low-income countries. ${ }^{7}$ In particular, the mortality related to postpartum hysterectomy varies from 11.9 per 100 hysterectomies in low-income settings compared with 2.5 per 100 hysterectomies in high-income settings (relative risk 4.8, 95\% CI 3.9-5.9). ${ }^{7}$ The maternal mortality rate is highest in low-income (12.1\%) and lowest in high-income settings $(1.4 \%)$.

Kazakhstan is one of the post-Soviet Central Asian republics, which achieved independence in 1991 and recently switched from lower-middle-income to upper-middle-income countries according to the World Bank classification. ${ }^{16}$ Population of the country composes 19 million with $26.7 \%$ of women in fertile age. ${ }^{17}$ Huge progress on reducing maternal mortality in Kazakhstan between 1990 and 2015 has been achieved ${ }^{18,19}$ and reported mortality rate in 2019 was 13.7 per 100,000 live births. ${ }^{20}$ To date, there is a lack of information about the statistics of peripartum hysterectomy and its common indications in Central Asian countries. Some available data come from small regional cohorts, ${ }^{21}$ however, it does not reflect the country-wide statistics. Taking into account this knowledge gap, we aimed to study the prevalence, indications, and outcomes of peripartum hysterectomy using nationwide large-scale health-care data from the national registry.

\section{Materials and Methods}

The study population consisted of hospitalized patients who underwent any type of peripartum hysterectomy in any Clinical setting of the Republic of Kazakhstan during the period of 2014-2018. The data was retrieved from the "Electronic Registry of Inpatients" which is one of the parts of the Unified Nationwide Electronic Health System (UNEHS), which was introduced at the end of 2013 to unify health-care data storage through the country healthcare system. The following variables were available in retrieved raw data: patient demographics (age, sex, ethnicity, location of residency), dates of hospital admission and discharge, International Statistical Classification of Diseases codes (ICD10 codes as the main diagnosis, clarifying diagnosis, comorbidities, and complications), discharge outcomes, hospital level and type of admission.

\section{Patient Selection and Definitions}

The initial cohort consists of overall 9,051,195 medical records of women registered for pregnancy, childbirth, and the puerperium follow-up. A total of 18,338 peripartum hysterectomy surgeries were identified using "68.30", “68.39", "68.40", and "68.49" ICD-9 procedural codes as selection criteria for this study. After removing duplicates and data cleaning, a dataset for 3848 surgery cases was extracted, which corresponds to 3838 patients (10 patients had second 


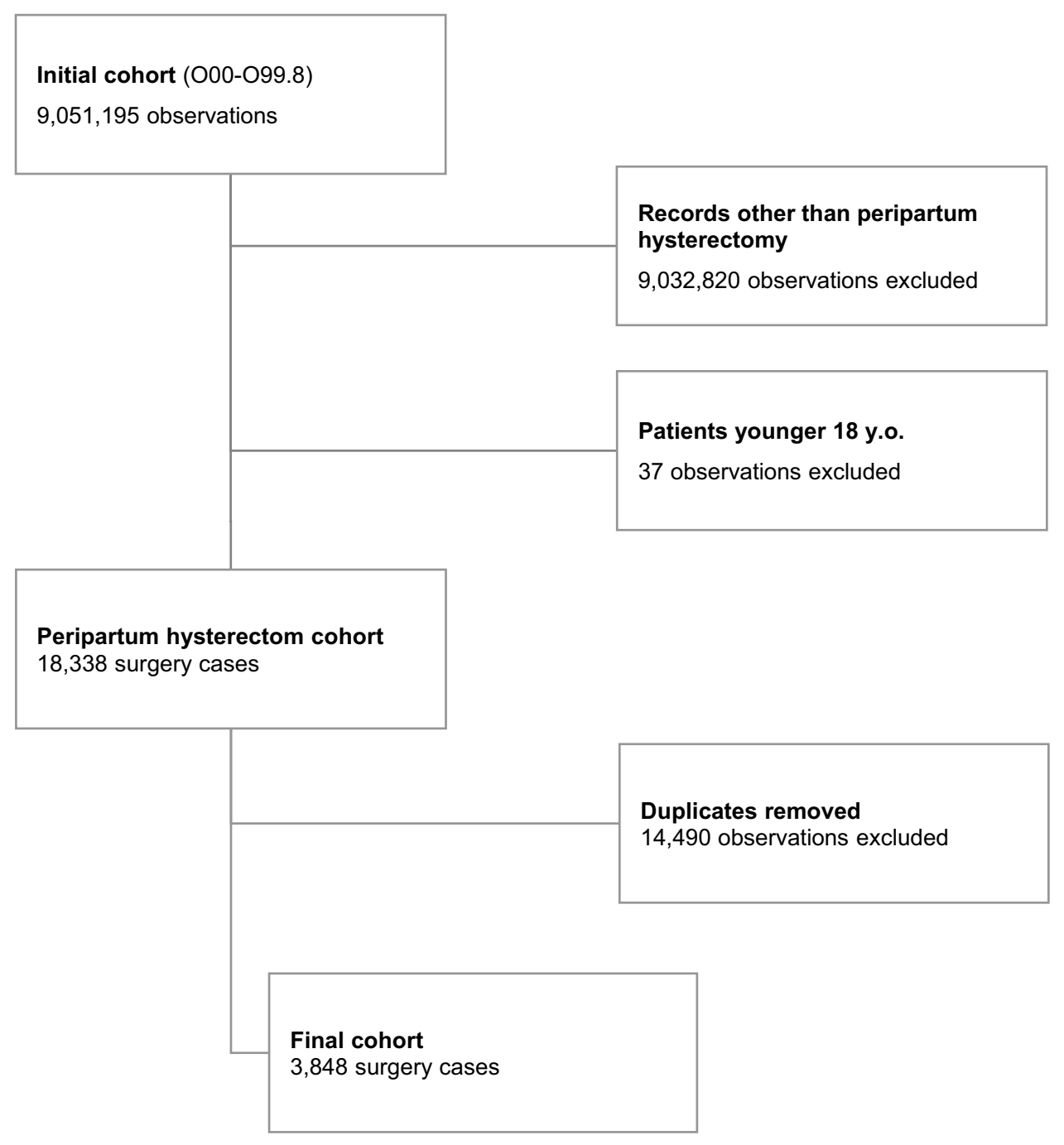

Figure I Patients' selection flow chart.

surgery). The detailed patient selection process is depicted in Figure 1. The rest of the peripartum hysterectomies were categorized to the total (ICD 68.40) and subtotal (ICD 68.30) by performed surgical approach. All available diagnoses were identified and grouped according to the ICD-10 code, and the full list of the diseases is provided in Supplementary Table 1. All available ICD-10 codes in the cohort are classified as the main diagnosis (up to 5), comorbidities or complications based on their direct indication in the cohort and/or based on their etiological-pathophysiological pathway.

\section{Statistical Analysis}

In the descriptive analysis, demographic characteristics of patients were presented in medians and interquartile ranges for continuous variables, in frequencies and percentages for categorical variables. Shapiro-Francia test and Q-Q plots were used to check variables for normality (Supplementary Figures 1 and 2). Age and hospital stay length were not normally distributed $(\mathrm{p}=0.00001)$; hence, median with interquartile range (IQR) was chosen to present the results. Two-sample $t$-test and chi-squared hypothesis testing were applied for bivariate analysis. In multivariable logistic regression analysis, we wanted to determine what factors are associated with total hysterectomy in comparison to subtotal hysterectomy. Categories with the largest number of patients were selected as reference groups. $P$ values are 2 -sided and reported as significant at $<0.05$ for all analyses. Data management and statistical analysis were performed using STATA 16 MP2 Version (STATA Corporation, College Station, TX). ${ }^{22}$ 


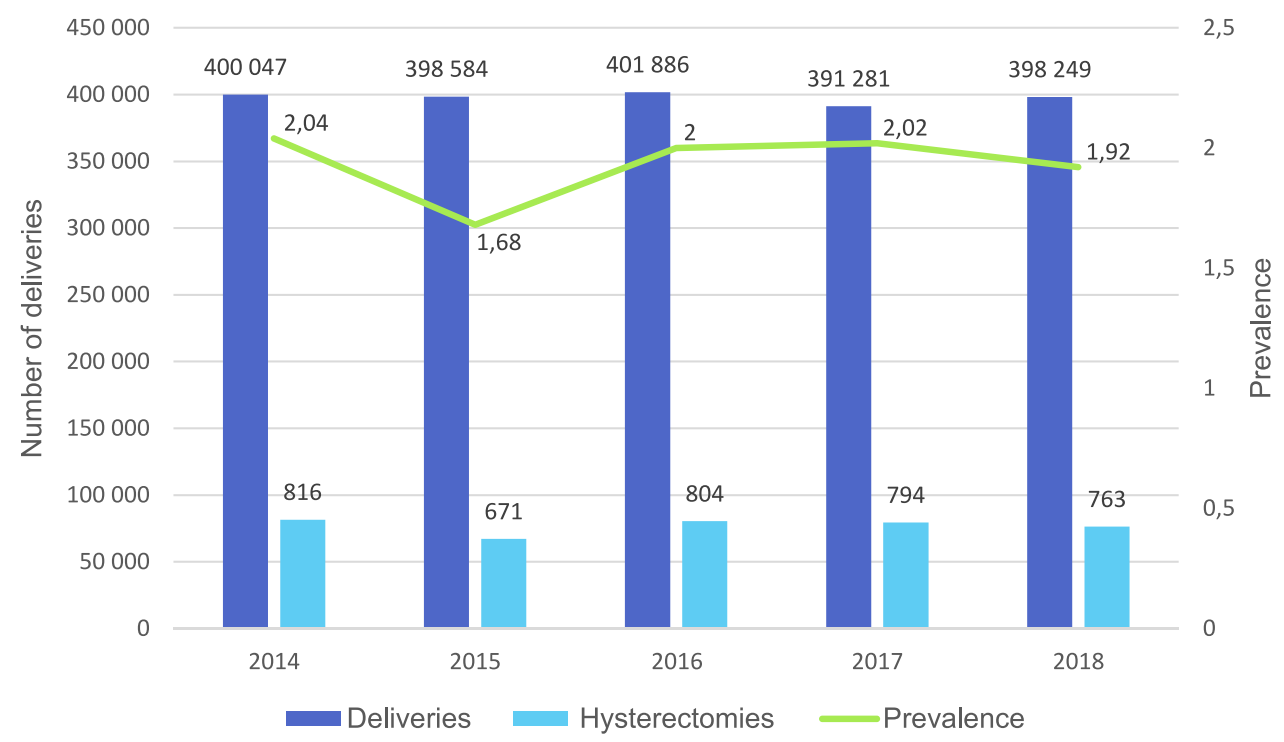

Figure 2 Prevalence of peripartum hysterectomy over 5-year period (2014-2018).

\section{Ethical Approval}

The study was conducted in compliance with the Declaration of Helsinki, and approved by the Nazarbayev University Institutional Review Ethics Committee (NU-IREC 203/29112019). Exemption from informed consent has been granted to this study due to the retrospective nature of the study in which only anonymous data were analyzed.

\section{Results}

\section{Analysis of Socio-Demographic Data}

In total, 3838 records of women who had a peripartum hysterectomy performed due to specific indications were identified and analyzed in the national electronic database for the period of 2014-2018 from all regions of Kazakhstan. For the period of 5 years (2014-2018), 3848 emergency peripartum hysterectomies were performed in 1,990,047 deliveries. Based on these data, the estimated prevalence of peripartum hysterectomies was calculated: overall weighted mean prevalence 1.93 per 1000 deliveries (Figure 2). Among all patients who had a peripartum hysterectomy performed due to the specific indications, $41.45 \%$ of patients had a vaginal delivery and $58.55 \%$ of women delivered via cesarean section.

A summary of the social and demographic characteristics of women is provided in Table 1. Maternal age ranged from 18 to 54 years, the median age of the participants was 33 (IQR 28-37) years, with 60.7\% of women aged between 18 and 34 years. Ethnic distribution of the investigated population includes $78 \%$ of Kazakh ethnicity, and $21.2 \%$ of other ethnic groups, including Russian.

The distribution of cases analyzed from the country regions was almost equal, but the largest number of peripartum hysterectomy cases were reported from the Turkestan region (20.2\%), Almaty region (12.8\%), and Almaty city (10.3\%). Out of all analyzed records, $87.8 \%$ of patients passed through the urgent admission route due to peripartum hemorrhage (Table 1). In $54 \%$ of cases, the peripartum hysterectomies were performed in tertiary care hospitals.

\section{Analysis of Indications and Techniques for Peripartum Hysterectomy}

Among the analyzed causes of peripartum hysterectomies, the leading indications were intrapartum hemorrhage (IPH) and PPH reported in $60 \%$ of the cases analyzed (IPH $-47.9 \%$, PPH $-12.1 \%$ ). The second most common indication was placental pathology - placental abruption and placenta previa in $9.6 \%$ and $7.9 \%$ of cases, respectively (Table 2). Some women had more than one indication. In $9.5 \%$ of the cases, the indication for peripartum hemorrhage was not recorded in the electronic system. The main diagnoses are presented in Figure 3. 
Table I Demographic Characteristics of Patients by Surgical Approach

\begin{tabular}{|c|c|c|c|c|c|}
\hline \multirow[t]{3}{*}{ Variables } & & \multirow{3}{*}{$\begin{array}{l}\text { Overall Patients } \\
(\mathbf{N}=3838) \\
\mathbf{N}(\%) \text { or } \\
\text { Median (IQR) }\end{array}$} & \multicolumn{3}{|c|}{ Hysterectomy Cases } \\
\hline & & & \multirow{2}{*}{$\begin{array}{l}\begin{array}{l}\text { Subtotal } \\
(\mathrm{N}=2 \text { I } 95)\end{array} \\
\mathrm{N}(\%) \text { or } \\
\text { Median (IQR) }\end{array}$} & \multirow{2}{*}{$\begin{array}{l}\begin{array}{l}\text { Total } \\
(\mathrm{N}=1633)\end{array} \\
\mathrm{N}(\%) \text { or } \\
\text { Median (IQR) }\end{array}$} & \multirow[t]{2}{*}{$\begin{array}{l}t \text {-Test or } \chi^{2} \\
\text { Test, } p \text {-value }\end{array}$} \\
\hline & & & & & \\
\hline Age, years & & $33(28 ; 37)$ & $33(28 ; 37)$ & $32(27 ; 37)$ & $<0.01$ \\
\hline \multirow[t]{3}{*}{ Age group } & $18-34$ & $2331(60.7 \%)$ & $1283(58.5 \%)$ & 1046 (64.1\%) & \multirow[t]{3}{*}{$<0.01$} \\
\hline & $35-44$ & |47| (38.3\%) & 888 (40.5\%) & $575(35.2 \%)$ & \\
\hline & $>45$ & $36(0.9 \%)$ & 24 (I.1\%) & $12(0.7 \%)$ & \\
\hline \multirow[t]{4}{*}{ Ethnicity } & Kazakh & 2996 (78.1\%) & 1729 (78.8\%) & 1256 (76.9\%) & \multirow[t]{4}{*}{0.21} \\
\hline & Russian & 367 (9.6\%) & 194 (8.8\%) & $173(10.6 \%)$ & \\
\hline & Other & 445 (II.6\%) & 252 (11.5\%) & 194 (11.9\%) & \\
\hline & Missing data & $30(0.8 \%)$ & $20(0.9 \%)$ & $10(0.6 \%)$ & \\
\hline \multirow[t]{17}{*}{ Region } & Akmola region & $103(2.7 \%)$ & 67 (3.1\%) & $36(2.2 \%)$ & \multirow[t]{17}{*}{$<0.01$} \\
\hline & Aktobe region & 117 (3.1\%) & $100(4.6 \%)$ & $16(1.0 \%)$ & \\
\hline & Almaty region & $489(12.8 \%)$ & 351 (I6.0\%) & 136 (8.3\%) & \\
\hline & Almaty city & $393(10.3 \%)$ & 95 (4.3\%) & 297 (I8.2\%) & \\
\hline & Atyrau region & $76(2.0 \%)$ & 46 (2.1\%) & $30(1.8 \%)$ & \\
\hline & East-Kazakhstan region & $189(4.9 \%)$ & 74 (3.4\%) & 116 (7.I\%) & \\
\hline & Zhambyl region & 164 (4.3\%) & $62(2.8 \%)$ & $102(6.3 \%)$ & \\
\hline & West-Kazakhstan region & $84(2.2 \%)$ & 31 (I.4\%) & $53(3.3 \%)$ & \\
\hline & Karaganda region & 225 (5.9\%) & $120(5.5 \%)$ & $106(6.5 \%)$ & \\
\hline & Kostanay region & $244(6.4 \%)$ & 173 (7.9\%) & $74(4.5 \%)$ & \\
\hline & Kyzylorda region & $130(3.4 \%)$ & 72 (3.3\%) & $56(3.4 \%)$ & \\
\hline & Mangystau region & $93(2.4 \%)$ & 74 (3.4\%) & $19(1.2 \%)$ & \\
\hline & Pavlodar region & $|7|(4.5 \%)$ & $56(2.6 \%)$ & $113(6.9 \%)$ & \\
\hline & North-Kazakhstan region & $92(2.4 \%)$ & $34(1.6 \%)$ & $58(3.6 \%)$ & \\
\hline & Turkestan region & 777 (20.2\%) & 569 (25.9\%) & $206(12.6 \%)$ & \\
\hline & Nur-Sultan city (capital) & $291(7.6 \%)$ & $142(6.5 \%)$ & 145 (8.9\%) & \\
\hline & Shymkent city & $200(5.2 \%)$ & $129(5.9 \%)$ & $70(4.3 \%)$ & \\
\hline \multirow[t]{2}{*}{ Location } & Urban & $2183(56.9 \%)$ & 1122 (5I.1\%) & 1057 (64.7\%) & \multirow[t]{2}{*}{$<0.01$} \\
\hline & Rural & 1655 (43.1\%) & $1073(48.9 \%)$ & $576(35.3 \%)$ & \\
\hline \multirow[t]{3}{*}{ Hospital level } & Primary & $772(20.1 \%)$ & $594(27.1 \%)$ & $176(10.8 \%)$ & \multirow[t]{3}{*}{$<0.01$} \\
\hline & Secondary & $990(25.8 \%)$ & 505 (23.0\%) & 485 (29.7\%) & \\
\hline & Tertiary & 2076 (54.1\%) & 1096 (49.9\%) & 972 (59.5\%) & \\
\hline
\end{tabular}


Table I (Continued).

\begin{tabular}{|c|c|c|c|c|c|}
\hline \multicolumn{2}{|l|}{ Variables } & \multirow{3}{*}{$\begin{array}{l}\text { Overall Patients } \\
(\mathbf{N}=3838) \\
\mathbf{N}(\%) \text { or } \\
\text { Median (IQR) }\end{array}$} & \multicolumn{3}{|c|}{ Hysterectomy Cases } \\
\hline & & & \multirow{2}{*}{$\begin{array}{l}\begin{array}{l}\text { Subtotal } \\
(\mathrm{N}=2 \text { I } 95)\end{array} \\
\mathrm{N}(\%) \text { or } \\
\text { Median (IQR) }\end{array}$} & \multirow{2}{*}{$\begin{array}{l}\begin{array}{l}\text { Total } \\
(\mathrm{N}=1633)\end{array} \\
\mathrm{N}(\%) \text { or } \\
\text { Median (IQR) }\end{array}$} & \multirow[t]{2}{*}{$\begin{array}{l}t \text {-Test or } \chi^{2} \\
\text { Test, } p \text {-value }\end{array}$} \\
\hline & & & & & \\
\hline \multirow[t]{2}{*}{ Type of admission } & Planned & $470(12.3 \%)$ & 345 (15.7\%) & $12 \mid(7.4 \%)$ & \multirow[t]{2}{*}{$<0.01$} \\
\hline & Emergency & 3368 (87.8\%) & I 850 (84.3\%) & 1512 (92.6\%) & \\
\hline Hospital stay length, days & & $10(8 ; 14)$ & $9(7 ; 12)$ & II $(9 ; 16)$ & $<0.01$ \\
\hline \multirow[t]{5}{*}{ Outcome of treatment } & Without changes & II 4 (3.0\%) & 73 (3.3\%) & $42(2.6 \%)$ & \multirow[t]{5}{*}{$<0.01$} \\
\hline & Recovery & 2477 (64.6\%) & 1498 (68.3\%) & $973(59.6 \%)$ & \\
\hline & Death & 41 (1.0\%) & $12(0.6 \%)$ & $29(1.8 \%)$ & \\
\hline & Improvement & 1193 (31.0\%) & $606(27.6 \%)$ & $582(35.6 \%)$ & \\
\hline & Deterioration & $13(0.3 \%)$ & $6(0.3 \%)$ & $7(0.4 \%)$ & \\
\hline
\end{tabular}

Table 2 Indications for Peripartum Hysterectomy

\begin{tabular}{|c|c|c|c|c|c|}
\hline \multirow[t]{3}{*}{ Indication/Diagnosis } & \multirow[t]{3}{*}{ ICD-I 0 Code } & \multirow{3}{*}{$\begin{array}{l}\text { Overall Cases } \\
\mathbf{N}(\%)\end{array}$} & \multicolumn{3}{|c|}{ Hysterectomy Cases } \\
\hline & & & \multirow{2}{*}{$\begin{array}{l}\text { Subtotal } \\
\mathbf{N}(\%)\end{array}$} & \multirow{2}{*}{$\begin{array}{c}\text { Total } \\
\mathbf{N}(\%)\end{array}$} & \multirow[t]{2}{*}{ Chi $^{2}$ Test, $\mathrm{p}$} \\
\hline & & & & & \\
\hline Labor and delivery complicated by intrapartum hemorrhage & O67 & 2919 (47.9\%) & $1665(81.0 \%)$ & 897 (66.3\%) & \multirow[t]{12}{*}{$<0.001$} \\
\hline Postpartum hemorrhage & O72 & $738(12.1 \%)$ & $99(4.8 \%)$ & II 8 (8.7\%) & \\
\hline Maternal tumor of corpus uteri with hemorrhage & O34.I & $721(11.8 \%)$ & $23(1.1 \%)$ & $22(1.6 \%)$ & \\
\hline Premature separation of placenta & O45.0 & $586(9.6 \%)$ & $82(4.0 \%)$ & $57(4.2 \%)$ & \\
\hline Placenta previa & O44.I & $478(7.9 \%)$ & $36(1.8 \%)$ & $43(3.2 \%)$ & \\
\hline Unspecified hemorrhage & O46.9 & $328(5.4 \%)$ & $172(4.8 \%)$ & $156(6.2 \%)$ & \\
\hline Rupture of uterus before onset of labor & O7I.0 & $58(1.0 \%)$ & $5(0.2 \%)$ & $12(0.9 \%)$ & \\
\hline Infection of amniotic sac and membranes & O4I.I & $20(0.3 \%)$ & $5(0.2 \%)$ & $2(0.2 \%)$ & \\
\hline Maternal care for intrauterine fetal death & O36.4 & $21(0.3 \%)$ & $12(0.3 \%)$ & $9(0.2 \%)$ & \\
\hline Amniotic fluid embolism & O88.I & $9(0.2 \%)$ & $2(0.01 \%)$ & $7(0.2 \%)$ & \\
\hline Inversion of uterus & N85.5 & I (0.02\%) & & I (0.04\%) & \\
\hline Unknown & - & $579(9.5 \%)$ & $202(5.7 \%)$ & 377 (14.9\%) & \\
\hline
\end{tabular}

Abbreviation: ICD, International Classification of Diseases.

An unspecified type of hysterectomy was reported in 20 (0.5\%) women (Figure 4). In the remaining 3828 (95.5\%), there were $1633(42.4 \%)$ total abdominal and 2195 (57.0\%) subtotal hysterectomies. There was a significant difference $(\mathrm{p}<0.001)$ between the surgical approach (total hysterectomy vs subtotal hysterectomy) between hospitals of the different levels (Table 1). The primary-level hospitals perform mostly subtotal hysterectomies (27.1\%), while tertiary- 


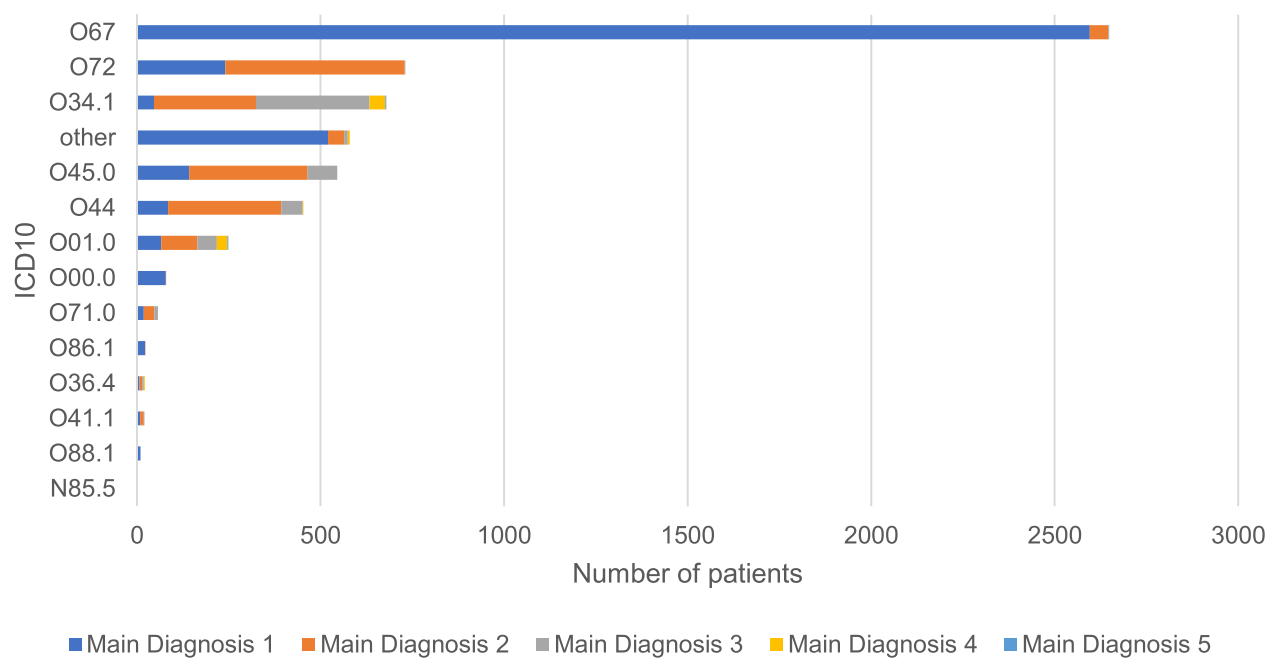

Figure 3 Number of patients by main diagnosis.

level hospitals utilize total hysterectomy in most cases (59.5\%) (Table 1). Total hysterectomy comprises only $10.8 \%$ of surgeries on the primary level and $46.9 \%$ on tertiary-level care.

In cases of peripartum hysterectomy due to IPH subtotal hysterectomy was performed in $81 \%$ of cases and total hysterectomy in $66.3 \%(\mathrm{p}<0.001)$. A significant difference was observed in the approach to PPH management as well (Table 2). However, there was no difference in the rates of total and subtotal hysterectomies in cases of placenta previa and placental abruption.

Additional surgical interventions after hysterectomy (relaparotomy) were reported for 10 patients due to the continuous hemorrhage. Out of the total cases analyzed, 41 patients $(1.07 \%)$ deceased after peripartum hysterectomy. Factors associated with hysterectomy type were included in a logistic regression model (Table 3). 35-44 years old age groups had a significantly lower $(\mathrm{OR}=0.8)$ chance to have total hysterectomy over subtotal hysterectomy. In the city of Almaty, the odds of getting a total hysterectomy were 6 times as high as in the Turkestan region. In contrast, patients in western regions Aktobe and Mangystau were $40 \%$ as likely undergoing total hysterectomy compared to the Turkestan

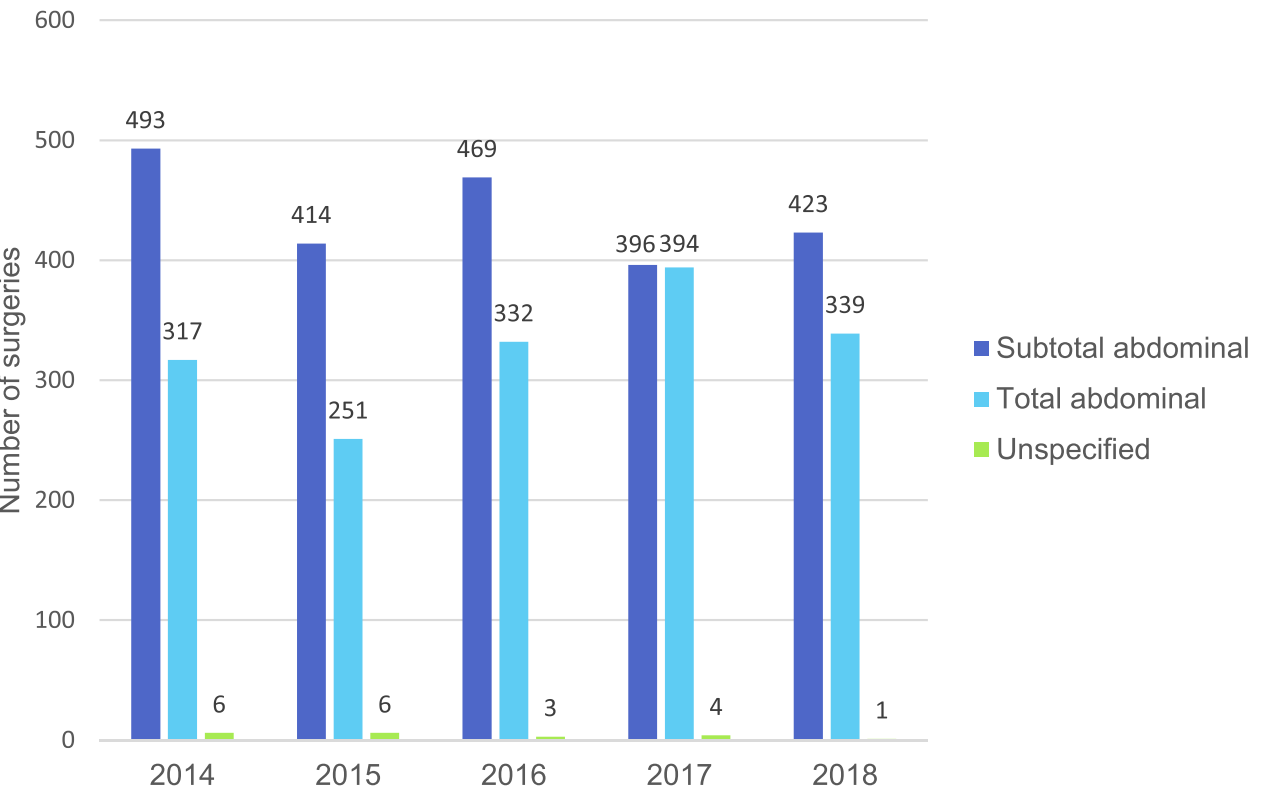

Figure 4 Number of peripartum hysterectomies for the period of 5 years (2014-2018). 
Table 3 Logistic Regression Model for Hysterectomy Type as an Outcome ( 0 - Subtotal, I - Total) with Other Factors

\begin{tabular}{|c|c|c|c|}
\hline \multicolumn{2}{|l|}{ Variables } & \multirow{2}{*}{$\begin{array}{l}\text { Adj. OR (95\% Cl) } \\
\text { Ref. }\end{array}$} & \multirow[t]{2}{*}{ p-value } \\
\hline Age group & $18-34$ & & \\
\hline & $35-44$ & $0.8(0.7 ; 0.9)$ & $<0.01$ \\
\hline & $45-50$ & $0.7(0.3 ; 1.6)$ & 0.42 \\
\hline \multirow[t]{17}{*}{ Region } & Akmola region & I.5 (I.0; 2.4) & 0.08 \\
\hline & Aktobe region & $0.4(0.2 ; 0.7)$ & $<0.01$ \\
\hline & Almaty region & I.I $(0.8 ; 1.4)$ & 0.48 \\
\hline & Almaty city & $6.6(4.8 ; 9.0)$ & $<0.01$ \\
\hline & Atyrau region & $1.9(1.2 ; 3.2)$ & 0.01 \\
\hline & East-Kazakhstan region & $3.6(2.5 ; 5.2)$ & $<0.01$ \\
\hline & Zhambyl region & $4.6(3.2 ; 6.7)$ & $<0.01$ \\
\hline & West-Kazakhstan region & $4.5(2.7 ; 7.3)$ & $<0.01$ \\
\hline & Karaganda region & $2.1(1.5 ; 2.9)$ & $<0.01$ \\
\hline & Kostanay region & $\mathrm{I} .0(0.7 ; \mathrm{I} .4)$ & 0.87 \\
\hline & Kyzylorda region & $2.1(1.4 ; 3.1)$ & $<0.01$ \\
\hline & Mangystau region & $0.5(0.3 ; 0.8)$ & 0.01 \\
\hline & Pavlodar region & $4.7(3.2 ; 6.9)$ & $<0.01$ \\
\hline & $\begin{array}{l}\text { North-Kazakhstan } \\
\text { region }\end{array}$ & $4.3(2.7 ; 6.9)$ & $<0.01$ \\
\hline & Turkestan region & Ref. & \\
\hline & Nur-Sultan city (capital) & $2.8(2.1 ; 3.9)$ & $<0.01$ \\
\hline & Shymkent city & $1.3(0.9 ; 1.8)$ & 0.20 \\
\hline \multirow[t]{3}{*}{ Ethnicity } & Kazakh & Ref. & \\
\hline & Russian & $0.9(0.7 ; 1.2)$ & 0.42 \\
\hline & Other & I.I (0.9; I.4) & 0.28 \\
\hline \multirow[t]{2}{*}{ Location } & Urban & Ref & \\
\hline & Rural & $1.0(0.8 ; 1.2)$ & 0.92 \\
\hline \multirow[t]{3}{*}{ Hospital level } & Primary & $0.5(0.4 ; 0.6)$ & $<0.01$ \\
\hline & Secondary & $1.0(0.9 ; 1.2)$ & 0.85 \\
\hline & Tertiary & Ref & \\
\hline \multirow[t]{2}{*}{ Admission } & Planned & $0.4(0.3 ; 0.5)$ & $<0.01$ \\
\hline & Emergency & Ref & \\
\hline Hospital stay duration & & $1.0(1.0 ; 1.1)$ & $<0.01$ \\
\hline
\end{tabular}


Table 4 Logistic Regression Model for Hysterectomy Type as an Outcome (0 - Subtotal, I - Total) with Main Diagnosis

\begin{tabular}{|l|l|r|}
\hline Main Diagnosis & Adj. OR (95\% Cl) & p-value \\
\hline O00.0 & $2.1(1.3 ; 3.3)$ & $<0.01$ \\
\hline O0I.0 & $2.2(1.3 ; 3.6)$ & $<0.01$ \\
\hline O34.I & $1.8(1.0 ; 3.2)$ & 0.06 \\
\hline O36.4 & $0.7(0.1 ; 3.8)$ & 0.72 \\
\hline O4I.I & $0.7(0.1 ; 3.8)$ & 0.72 \\
\hline O44 & $2.2(1.4 ; 3.5)$ & $<0.01$ \\
\hline O45.0 & $1.3(0.9 ; 1.8)$ & 0.15 \\
\hline O67 & Ref. & 0.01 \\
\hline O7I.0 & $4.5(1.6 ; 12.7)$ & $<0.01$ \\
\hline O72 & $2.2(1.7 ; 2.9)$ & $<0.01$ \\
\hline O86.I & $18.6(4.3 ; 79.6)$ & 0.02 \\
\hline O88.I & $6.5(1.3 ; 31.3)$ & $<0.01$ \\
\hline Other & $2.7(2.0 ; 3.8)$ & \\
\hline
\end{tabular}

region. The primary-level hospital was associated with a twice lower chance to provide total hysterectomy over subtotal than a tertiary-level hospital. Patients who were admitted in a planned manner were less likely $(\mathrm{OR}=0.4)$ to receive total hysterectomy than emergency patients. Fatal cases were highly associated with total hysterectomy than with subtotal one. Longer hospital stay increased the odds $(\mathrm{OR}=1.1)$ to undergo a total hysterectomy.

Hysterectomy type outcome was assessed by main diagnoses. Patients with O67 diagnosis were taken as reference $(\mathrm{OR}=1$ for total hysterectomy instead of subtotal hysterectomy). Patients with main diagnoses other than 067 had higher odds to go through a total hysterectomy, while patients with $\mathrm{O} 34.1$ and $\mathrm{O} 36$ had lower $(\mathrm{OR}=0.7)$, although not statistically significant, likelihood to get total hysterectomy (Table 4). Participants with O86.1 had an almost 20-fold higher risk of having a total uterus removal procedure.

\section{Discussion}

Kazakhstan is one of the post-Soviet republics of Central Asia. The collapse of the Soviet Union led Kazakhstan to an economic recession, and the country's healthcare system has gone through decades of profound revolutions. Despite recent improvements in the healthcare system, Kazakhstan still lags behind some other post-Soviet independent states with only $3.4 \%$ of gross domestic product (GDP) allocated for the healthcare system, while the average expenditures in the neighboring countries are around $6.5 \%{ }^{9}{ }^{9,15}$ Although significant improvement was achieved in the prevention and management of PPH as a main obstetric near-miss, maternal mortality rates remain high in Kazakhstan. ${ }^{10,23,24}$ To our knowledge, this is the first study to identify the prevalence, indications, and outcomes of peripartum hysterectomy in Kazakhstan using nationwide large-scale health-care data for the period of 5 years (2014-2018).

In our study, a total of 3848 peripartum hysterectomy cases were analyzed. The study findings reveal that the distribution of peripartum hysterectomy cases analyzed from the country regions was almost equal with the largest number of surgeries reported from the Turkestan region (20.2\%), Almaty region (12.4\%), and Almaty city (10.3\%). High rates of peripartum hysterectomies in Turkestan, Almaty city, and Almaty region could be explained by the high density of the population in these territories with the respectively high birth rates. Moreover, as Almaty is the biggest city in the country (population is more than 2 million), the number of tertiary care hospitals accumulating severe cases and 
performing hysterectomies in this city is more than in the other Kazakhstani regions. It also could contribute to the discrepancy in the distribution of cases/surgeries.

In our study, IPH and PPH were reported as the leading indications for peripartum hysterectomy, while placental pathology (placenta previa and placental abruption) was the second most common indication. Our findings are different from the majority of international previously published studies investigating indications for peripartum hysterectomies where placental pathology (placenta previa, abnormally attached placenta) was reported as the most common indication for peripartum hysterectomy (47.6-53.7\%). ${ }^{7,25-27}$ Having IPH and PPH as leading indications for peripartum hysterectomy in Kazakhstan suggests that obstetric care during labor/delivery should be reinforced and the PPH prevention and management guideline should be strictly followed.

In $9.5 \%$ of the cases reported in our study, the indication for peripartum hysterectomy was not recorded in the electronic system. It may be explained by the imperfection and misuse of the system at the time of its introduction in 2013. The same as in other studies, ${ }^{7}$ some women had more than one indication for surgery.

Our study found that the subtotal abdominal hysterectomy approach is used more commonly (in $57 \%$ of cases) than a total hysterectomy (in $42.4 \%$ of cases). Moreover, there is a significant difference between the surgical approaches (total hysterectomy vs subtotal hysterectomy) between hospitals of the different levels, with more subtotal hysterectomies performed in primary-level hospitals. This might be explained by the absence of experienced gynecologists who could perform a total hysterectomy in the primary-level hospitals and specific obstetric care regulations implemented in the country. According to these regulations, primary-level hospitals admit relatively stable cases, while severe cases should be transferred to the tertiary-level hospitals in advance to prevent adverse outcomes.

Among all analyzed peripartum hysterectomy ceases, $87.8 \%$ of patients were admitted urgently. Since the vast majority of peripartum hysterectomies had been performed as urgent surgery, it increases the risks of complications and adverse outcomes. Similar conclusions noted by previous reports from European countries and worldwide. ${ }^{6,7,13}$

The prevalence of peripartum hysterectomy was relatively stable during the analyzed period, varying from 1.68 to 2.02 per 1000 deliveries. It is higher than in developed countries where the incidence and prevalence are as low as 0.2 per 1000 deliveries and comparable with other upper-middle-income countries. ${ }^{6,7,26,27}$ Unfortunately, there are no available data from other post-Soviet republics with the same income to compare the prevalence rates.

The current study has some strengths and limitations. This study is the first attempt to identify the prevalence of peripartum hysterectomy and identify its common indications across the country using nationwide electronic health-care records. This summary gives us an understanding of gaps in the national healthcare system and will help to reinforce the PPH management as the main obstetric near-miss. Nevertheless, the study has some limitations related to the national health-care electronic recording system imperfections. The system does not provide detailed information on patients' past medical history. Some cases of misreporting the patients' data were identified during this analysis.

\section{Conclusion}

This study reported the prevalence of peripartum hysterectomies in Kazakhstan, comparable with other upper-middle-income countries. However, in contrast with similar studies, IPH and PPH remain the main indications of peripartum hysterectomy, which highlights the importance of proper patient follow-up during the labor/delivery process. Although significant improvement was achieved in the decrease of maternal mortality rates in Kazakhstan, PPH management and peripartum hysterectomy rates require the attention of national health-care providers. Appropriate maternal care during labor and delivery based on the suggested PPH prevention guidelines may decrease rates of peripartum hysterectomy in Kazakhstan, thus, will improve maternal mortality rates. Further investigation is necessary to fully understand the underlying factors that contribute to the incidence of peripartum hysterectomy and to determine optimal management strategies.

\section{Data Sharing Statement}

All data related to this study are available from Republican Center for Electronic Health of the Ministry of Health of the Republic of Kazakhstan, but restrictions apply to the availability of these data, which were used under the contractagreement for the current study, and so are not publicly available. Data are, however, available from the authors 
(abduzhappar.gaipov@nu.edu.kz) upon reasonable request and with permission of Ministry of Health of the Republic of Kazakhstan.

\section{Funding}

This study was supported by grants from the Nazarbayev University Faculty Development Research Grant Program FDCRGP 2020-2022 (Funder Project Reference: 240919FD3913). The funder had no role in study design, data collection and analysis, decision to publish, or preparation of the manuscript. A.G. is a PI of the projects.

\section{Disclosure}

The authors report no conflicts of interest in this work.

\section{References}

1. Orhan A, Ozerkan K, Kasapoglu I, et al. Laparoscopic hysterectomy trends in challenging cases (1995-2018). J Gynecol Obstet Hum Reprod. 2019;48(10):791-798. doi:10.1016/j.jogoh.2019.06.007

2. Ramdhan RC, Loukas M, Tubbs RS. Anatomical complications of hysterectomy: a review. Clin Anat. 2017;30(7):946-952. doi:10.1002/ca.22962

3. Harnod T, Chen W, Wang JH, Lin SZ, Ding DC. Hysterectomies are associated with an increased risk of depression: a Population-Based Cohort Study. J Clin Med. 2018;7(10):366. doi:10.3390/jcm7100366

4. Dedden SJ, Geomini PMAJ, Huirne JAF, Bongers MY. Vaginal and laparoscopic hysterectomy as an outpatient procedure: a systematic review. Eur J Obstet Gynecol Reprod Biol. 2017;216:212-223. doi:10.1016/j.ejogrb.2017.07.015

5. Clarke-Pearson DL, Geller EJ. Complications of hysterectomy. Obstet Gynecol. 2013;121:654-673. doi:10.1097/AOG.0b013e3182841594

6. Kallianidis AF, Maraschini A, Danis J, et al. Epidemiological analysis of peripartum hysterectomy across nine European countries. Acta Obstet Gynecol Scand. 2020;99(10):1364-1373. doi:10.1111/aogs.13892

7. van den Akker T, Brobbel C, Dekkers OM, Bloemenkamp KWM. Prevalence, indications, risk indicators, and outcomes of emergency peripartum hysterectomy worldwide: a systematic review and meta-analysis. Obstet Gynecol. 2016;128(6):1281-1294. doi:10.1097/AOG.0000000000001736

8. Committee on Practice Bulletins-Obstetrics. Practice bulletin No. 183: postpartum hemorrhage. Obstet Gynecol. 2017;130(4):e168-e186. doi:10.1097/AOG.0000000000002351

9. World Health Organization. The world health statistics; 2020. Available from: https:/www.who.int/data/gho/publications/world-health-statistics. Accessed September 22, 2021.

10. Evaluating the quality of care for severe pregnancy complications: the WHO near-miss approach for maternal health; 2011. Available from: http:// apps.who.int/iris/bitstream/10665/44692/1/9789241502221_eng.pdf. Accessed September 23, 2021.

11. Najam R, Bansal P, Sharma R, Agarwal D. Emergency obstetric hysterectomy: a retrospective study at a tertiary care hospital. J Clin Diagn Res. 2010;4:2864-2868.

12. Sakse A, Weber T, Nickelsen C, Secher NJ. Peripartum hysterectomy in Denmark 1995-2004. Acta Obstet Gynecol Scand. 2007;86:1472-1475. doi:10.1080/00016340701692651

13. Gyamfi-Bannerman C, Srinivas SK, Wright JD, et al. Postpartum hemorrhage outcomes and race. Am J Obstet Gynecol. 2018;219(2):185.e1-185. e10. doi:10.1016/j.ajog.2018.04.052

14. Newsome J, Martin JG, Bercu Z, Shah J, Shekhani H, Peters G. Postpartum hemorrhage. Tech Vasc Interv Radiol. 2017;20(4):266-273. doi:10.1053/j.tvir.2017.10.007

15. Higgins MF, Monteith C, Foley M, O’Herlihy C. Real increasing incidence of hysterectomy for placenta accreta following previous caesarean section. Eur J Obstet Gynecol Reprod Biol. 2013;171:54-56. doi:10.1016/j.ejogrb.2013.08.030

16. The World Bank country classification by income. Available from: https://data.worldbank.org/country. Accessed September $23,2021$.

17. The world population clock. Available from: https://www.worldometers.info/world-population/kazakhstan-population/. Accessed August 31, 2021.

18. Organisation for Economic Co-operation, Development. OECD Reviews of Health Systems: Kazakhstan 2018. Paris: OECD Publishing; 2018.

19. Colet P, Aimagambetova G, Kossybayeva K. Evidence-based inpatient postnatal care among women in a national hospital in Kazakhstan: a best practice implementation project. JBI Evid Implement. 2020;18(3):318-326. doi:10.1097/XEB.0000000000000234

20. The ministry of healthcare of the Republic of Kazakhstan report; 2019. Available from: http://www.rcrz.kz/index.php/ru/statistikazdravookhraneniya-2. Accessed September 23, 2021.

21. Nadisauskiene RJ, Dobozinskas P, Kacerauskiene J, et al. The impact of the implementation of the postpartum haemorrhage management guidelines at the first regional perinatal centre in Southern Kazakhstan. BMC Pregnancy Childbirth. 2016;16:238. doi:10.1186/s12884-016-1027-4

22. StataCorp LLC. Stata statistical software: release 16; 2019.

23. GBD 2015 Maternal Mortality Collaborators. Global, regional, and national levels of maternal mortality, 1990-2015: a systematic analysis for the Global Burden of Disease Study 2015 [published correction appears in Lancet. 2017 Jan 7;389(10064):e1]. Lancet. 2016;388(10053):1775-1812. doi:10.1016/S0140-6736(16)31470-2

24. Morris JL, Khatun S. Clinical guidelines-The challenges and opportunities: what we have learned from the case of misoprostol for postpartum hemorrhage. Int J Gynaecol Obstet. 2019;144(1):122-127. doi:10.1002/ijgo.12704

25. Barinov SV, Medjannikova IV, Tirskaya YI, et al. The use of Zhukovsky vaginal and intrauterine balloons to improve the outcome of postpartum hysterectomies in patients with severe bleeding. J Maternal-Fetal Neonatal Med. 2019:1-121. doi:10.1080/14767058.2019.1566309

26. Gari A, Tahir F, Latifah H, Hafidh B, Tawfiq A, Almatrafi M. Cesarean hysterectomy: a 10-year retrospective review in Jeddah, Saudi Arabia. J Gynecol Women's Health. 2021;22(1). doi:10.19080/JGWH.2021.22.556078

27. Uysal D, Cokmez H, Aydin C, Ciftpinar T. Emergency peripartum hysterectomy: a retrospective study in a tertiary care hospital in Turkey from 2007 to 2015. J Pak Med Assoc. 2018;68(3):487-489. PMID: 29540895. 


\section{Publish your work in this journal}

The International Journal of Women's Health is an international, peer-reviewed open-access journal publishing original research, reports, editorials, reviews and commentaries on all aspects of women's healthcare including gynecology, obstetrics, and breast cancer. The manuscript management system is completely online and includes a very quick and fair peer-review system, which is all easy to use. Visit http://www. dovepress.com/testimonials.php to read real quotes from published authors.

Submit your manuscript here: https://www.dovepress.com/international-journal-of-womens-health-journal 